\title{
Migraciones a debate. Las cuestiones políticas en la época de los regímenes de terror
}

\author{
YERKO CASTRO NEIRA
}

El trabajo revisa los cambios fundamentales para las migraciones y los migrantes que se suceden después de septiembre de 2001, cuando inicia una época de securitización o de regímenes de terror. Se expone una serie amplia de aporías y contradicciones que se establecen entre los discursos y las acciones para proteger y garantizar los derechos de los migrantes, y la tendencia múltiple y diversa que los criminaliza y los convierte en personas inmersas en contextos de violencia. Esto se explica a partir de seis tesis primordiales presentes en estos fenómenos, en las que se abunda a través de la discusión con dos viñetas etnográficas extraídas del trabajo de campo.

PALABRAS CLAVE: migración, regímenes de terror, securitización, política, violencia y ley

Migration to Debate. Political Issues at the Time of the Regimes of Terror

This paper reviews the fundamental changes to migration and migrants after $9 / 11$, when an era of securitization or terror regimes began. It presents a wide range of paradoxes and contradictions between speeches and actions to protect and guarantee the migrants rights, and the multiple and diverse tendency to criminalize them and put them into contexts of violence. I develop six primary theses present in these phenomena. I explain them through discussion with two vignettes drawn from ethnographic fieldwork.

KEYWORDS: migration, terror regimes, securitization, politics, violence and law 


\section{Introducción}

Aconteceres muy frecuentes, si no una constante en la historia, son los movimientos o migraciones de pueblos. Unas veces esas marchas han sido voluntarias y otras obligadas. [...] En ese contexto se inscribe el establecimiento de ingleses que, huyendo de persecuciones religiosas, penetraron en Norteamérica y fueron ensanchando sus territorios a expensas de los indios, repelidos una y otra vez y encerrados a la postre en reservas [...] ¿qué habrá que pensar acerca de los miles de africanos que tratan de penetrar en Europa, obviamente "sin papeles", como tampoco los tuvieron quienes incursionaron antes en sus tierras? Los africanos, que fueron desposeídos por sus antiguos dominadores, se trasladan ahora en busca de trabajo y recursos. Exponen sus vidas en sus migraciones pero están decididos a "pagar la visita" a los descendientes de quienes fueron sus amos [...] Si muchos de los antepasados de quienes hoy viven en los países ricos migraron, conquistaron y penetraron en tierras distantes en busca de riquezas, ¿̇es extraño que los de esas tierras hoy se pongan en marcha en busca también no ya de oro y diamantes sino siquiera de fuentes de trabajo para salir de su miseria y la de sus propias familias? (León-Portilla, 2006).

Ser subdesarrollado no es sólo ser despojado o explotado, es estar atado a una perpetua estasis artificial. El subdesarrollado no solamente mata, su estancamiento esencial niega la vida y se asemeja a la muerte. El migrante quiere vivir. No es únicamente la pobreza lo que lo obliga a emigrar. Con su esfuerzo individual intenta lograr el dinamismo que le falta a la situación en que nació (Berger y Mohr, 2011: 46).

os años noventa del siglo pasado fueron buenos años, al menos en el imaginario académico que miraba la migración. El auge de estudios que hablaban de remesas, la cuantificación de los fenómenos de movilidad humana y sus impactos económicos hacían pensar en el poder económico que generaban los migrantes en Estados Unidos y en sus lugares de origen. Investigaciones cualitativas, del mismo modo pero con otras fuentes, revelaban innumerables posibilidades emancipatorias 
en las migraciones internacionales. Estudios como los de Kearney (1996) o Glick, Basch y Blanc-Szanton (1992) sostenían con base en historias de vida y experiencias de desplazamientos de familias y comunidades que las conexiones y vínculos que los migrantes mantenían con sus lugares de origen transformaban en relevantes los nuevos espacios sociales transnacionales. Por supuesto, estas investigaciones también podían destacar aspectos negativos y situaciones de trauma en las migraciones internacionales, pero lo que digo es que los noventa y los fenómenos que allí aparecían más claros llevaron a un amplio número de investigadores a pensar en las posibilidades económicas y políticas de unos migrantes que parecían desafiar el nuevo orden global y con ello poner en serios aprietos a los Estados nacionales como paradigma fundante de todo lo social.
Los años noventa terminaron. Inició un periodo en el que cayeron las Torres Gemelas en Estados Unidos al mismo tiempo que se desvanecían todos esos buenos augurios que caracterizaron la década anterior. A partir de septiembre de 2001 se hizo evidente que estábamos entrando a un nuevo momento de posguerra fría en el que los paradigmas fundamentales podían definirse como regímenes de terror. En esta época de la seguridad, claro, los migrantes no han salido bien parados. Se trata de un momento en que los migrantes y los movimientos masivos de población aparecen como un problema de seguridad nacional para los países, para los que toda política hacia los migrantes es de securitización (Doty, 2007; Pallitto y Heyman, 2008; Locas, 2011) y la criminalización de las singularidades y de las experiencias se dibuja como

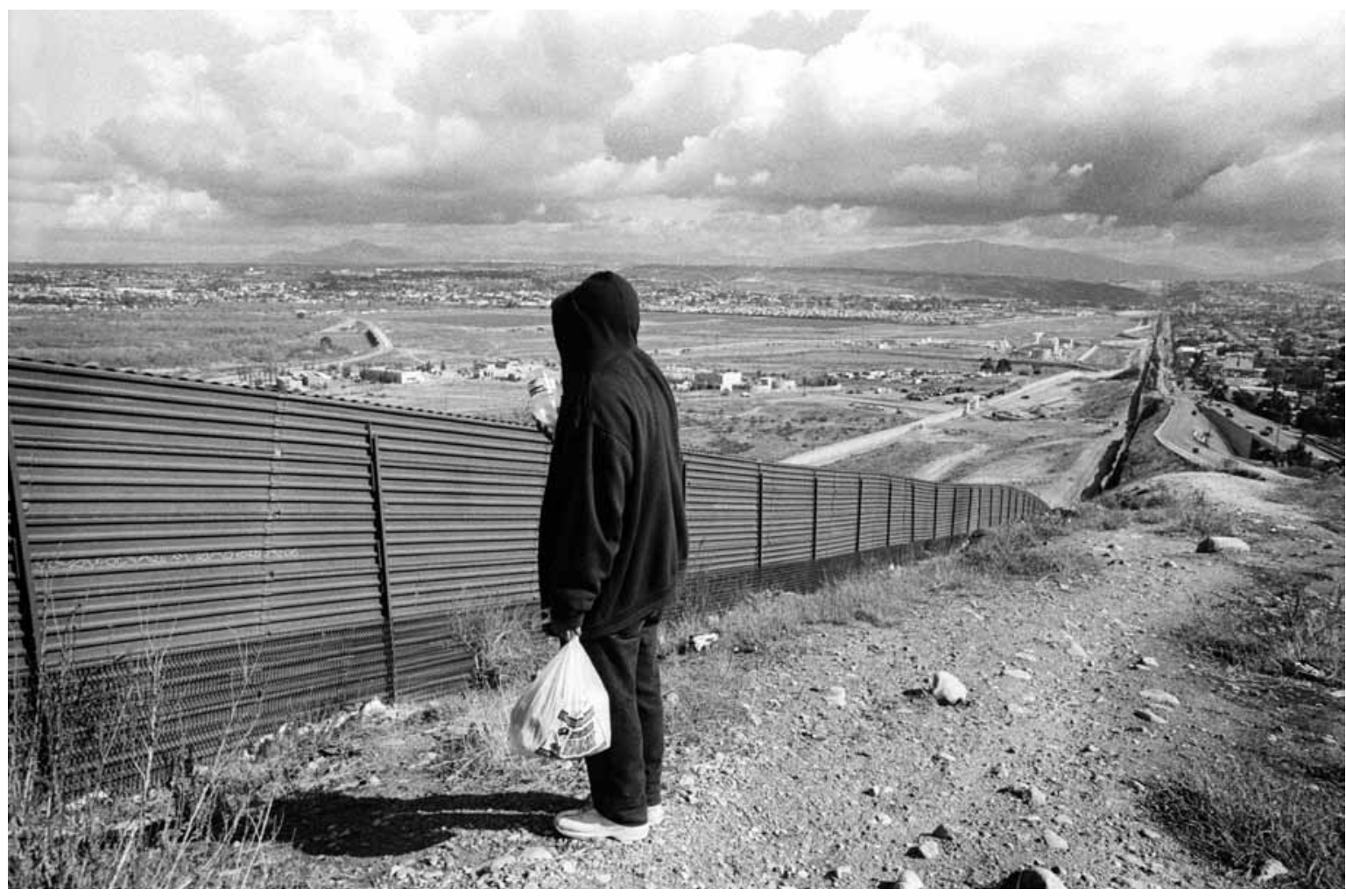

Elsa Medina Castro • Barda fronteriza / Playas de Tijuana, B. C., 2007, Frontera México/Eua. 
más importante, más relevante e incluso urgente que cualquier otra cosa.

La migración internacional se ha desplazado hasta el primer lugar de las agendas de seguridad internacional en Estados Unidos, Europa y el resto del mundo. Fiona Adamson insiste en que mucho de esta discusión se ha enfocado en ver a los flujos migratorios como un conducto de transmisión para el terrorismo internacional (Adamson, 2006: 165). Un balance de los últimos 10 años en las migraciones internacionales, con énfasis en México, debe partir por reconocer el momento de crisis que las afecta. Luego del fin de la Guerra Fría y a partir de los ataques de septiembre de 2001 en Estados Unidos, la naturaleza y la función de las fronteras se han transformado al punto de reforzar las dinámicas de seguridad y acorazar todas las políticas de fronterización. El migrante vuelve a estar en el centro de la escena moderna, pero esta vez indisolublemente asociado a los problemas de seguridad. Aunque esta situación no puede presentarse como totalmente nueva, con la globalización y las migraciones internacionales se han multiplicado y diversificado el número de amenazas al Estado por parte de actores no estatales. El ejemplo más palpable de esto es Estados Unidos, donde a partir de septiembre de 2001 se ha producido la mayor reorganización del gobierno desde el Acta de Seguridad Nacional de 1947 (Adamson, 2006: 165). ${ }^{1}$

Las antinomias que esto representa son múltiples. Algunos autores han concebido una de éstas como parte de la "paradoja liberal", es decir, las fuerzas económicas que empujan a los Estados hacia una gran apertura que garantice la competencia, el comercio y la inversión, y por otra parte las fuerzas que insisten en ver los movimientos migratorios como un gran riesgo y una amenaza política (Ho1lifield, 2004: 885). Las tareas centrales de los Estados pueden definirse en tres áreas fundamentales: el mantenimiento de la seguridad, la construcción de regímenes de comercio e inversión y la regulación de la migración (Hollifield, 2004: 885). A pesar de que han pasado varios años desde el fin de la Guerra Fría, estas funciones importantes de los Estados continúan articulándose más a la figura de un "garrison state" que a un momento de democracia abierta y libre del todo. Es decir, en el orden de estas tareas hay mayor preeminencia de los especialistas en la violencia y la seguridad que de los expertos en comercio y libre mercado (Lasswell, 1941).

En este artículo quiero trabajar estas ideas para discutir cómo las migraciones y los migrantes han llegado a estar en el centro de la escena global contemporánea y al hacerlo han cuestionado el estatuto mismo de lo político. Dicho de otra manera, la crisis por la que atraviesan los migrantes es principalmente de orden político - de lo político y de la políti$\mathrm{ca}-,{ }^{2}$ lo cual encierra una seria polémica en torno a todos los órdenes de lo social, a las definiciones de cualquier contrato de sociabilidad y a la propia concepción del ser humano y los supuestos derechos que le son inalienables y constitutivos. Para hacer esto, mencionaré las seis tesis fundamentales que me guían. Acto seguido, pondré “a trabajar” estas tesis con dos viñetas etnográficas ${ }^{3}$ que configuran campos en los que la migración se experimenta y se produce.

1 Más adelante mencionaré la manera en que han afectado a la frontera algunas de estas modificaciones, como las ocurridas con la Guardia Nacional, la Patrulla Fronteriza y la Oficina Federal de Información de Estados Unidos.

$2 \quad$ Nancy establece una diferencia entre lo político y la política. Lo primero se refiere a los asuntos en común, de todos y que convocan a los asuntos públicos. La segunda, en cambio, apela a la forma de administración determinada de esos asuntos de todos (Nancy, 2007).

3 Por viñetas etnográficas entiendo la presentación del material de campo que proviene de distintos nichos de observación antropológica. Aquí me refiero a dos cosas: por un lado, materiales y elementos derivados de etnografías multisituadas que he hecho en pueblos migrantes de Oaxaca en California y, por otro, el resultado de etnografías de la ley, estudios y análisis que surgen de tomar las nuevas leyes migratorias como campos de observación. 
Las preguntas que organizan el trabajo son dos y de dos tipos. En primer lugar, al describir fenómenos de actualidad en las migraciones internacionales, me interesa comprender cuáles son los nuevos signos y rasgos que definen la política y la violencia en los procesos de movilidad humana en clave histórica después de septiembre de 2001. En segundo término, más analíticamente, me interesa discutir cómo explicar la antinomia fundamental e irrepresentable que encierran estos problemas, es decir, que toda política elaborada en nombre de la securitización y la seguridad descansa en la violencia contra los migrantes y los viajeros subalternos. Expresado en perspectiva biopolítica: ¿cómo toda política de seguridad conlleva necesariamente la producción múltiple y constante de inseguridades?, ¿cómo toda acción política que tiende a proteger y cuidar la vida es al mismo tiempo una política que se enlaza y que produce muerte? Observar a los migrantes nos puede llevar a posibles respuestas.

\section{Las tesis principales del fenómeno}

La migración es un fenómeno vasto, amplio y complejo, de lo que se desprende que cualquier presentación de sus debates será incompleta. Las tesis que presentaré ahora subrayan los rasgos de precariedad y violencia en que se mueven gran parte de las migraciones globales, por lo que daré una mirada, si se quiere, particular al fenómeno. En consecuencia, dejaré de lado las historias de éxito y de movilidad laboral y de clase que existen y aparecen de vez en cuando. Ahora bien, al observar las migraciones internacionales desde el surgimiento de los paradigmas de securitización y de los consecuentes regímenes del terror que le son constitutivos (Tirman, 2004; Chebel, 2012), asoma la permanente e inseparable relación entre las migraciones y sus múltiples violencias asociadas. De este modo, migración y política deben leerse a partir de las violencias que las definen.
En este sentido, se confirma la tesis benjaminiana que postula que la violencia se explica por la política y toda política se explica a su vez por las violencias (Benjamin, 2007). En los fundamentos de lo político descansa la violencia como asunto constitutivo, de lo cual se desprende la primera tesis de este documento, la del fundamento de lo político: la política confirma y profundiza la vulnerabilidad de los migrantes. Además de su carácter fundante, las migraciones se confirman por su propia historicidad. Mirado en perspectiva del tiempo, las migraciones y la movilidad humana han estado asociadas a las violencias en los más variados sitios de producción. Como explica Bolaños, hay cierta continuidad histórica desde el derecho romano, pasando por el comercio de esclavos hasta llegar al trabajo "ilegal" que acompaña a innumerables sectores de la economía capitalista, continuidad que se expresa en la tensión que confirma la figura de extraños —extraneus - y la de excluidos - extrarius - (Bolaños, 2012: 26-29).

El esclavo romano sintetizaba bien esta figura. Casi siempre extranjero, era jurídicamente definido por su exclusión de la comunidad política. Extraño o extranjero, y excluido por medio de un bando soberano (Agamben, 2006), convertido en categoría de persona en permanente suspensión de sus derechos. ${ }^{4} \mathrm{La}$ esclavitud no sólo fue fundamental para conformar la diáspora negra por el mundo (Hall, 1990). En cuanto actividad comercial fue una de las bases de toda economía capitalista. Contrario a la tendencia a ubicar a la industria textil como el fundamento concreto del cual parte el capitalismo, quiero enfatizar como rasgos originarios del comercio de ultramar el colonialismo, el despojo y la violencia que lo acompañan. Gracias al colonialismo, Europa pasó de abarcar y dominar 35\%

4

En un sentido similar, pero apuntando más bien a la dimensión alienante de la esclavitud, Marx (2001) define a los esclavos como extranjeros de sí mismos. 
del planeta en 1815 a $85 \%$ a finales del mismo siglo (Said, 2003: 64). Con la abolición de la esclavitud, sin embargo, la producción política del extranjero y el excluido no cesarán. Al contrario, los migrantes serán parte de esa categoría de personas que idealmente reunirán las cualidades de extranjero y excluido al mismo tiempo, de ahí se desprende la segunda tesis: se confirma la condición histórica de exclusión de los migrantes — tesis genealógica-.

Hasta aquí he anunciado una tercera dimensión el problema. Los migrantes aparecen como categoría que la ley produce siempre como exclusión. Los migrantes son tierra de nadie en materia jurídica, como advierten De Sousa y García (2004). Esto significa que no existe un "afuera de la ley", al contrario, la exclusión de los migrantes o su ilegalización confirma el estatuto violento de la ley y de todo lo político. Es decir, el carácter excepcional de los migrantes, su dimensión clandestina y silenciosa para la ley, en lugar de colocarlos afuera de la política real o imaginaria, los traslada al centro mismo de la actuación o expresión política, lo que ayuda a confirmar la definición de la ley como productora de excepcionalidades.

Agamben observa esto en los centros de detención para migrantes sin documentos en Italia. Sostiene que ellos son ejemplo de un salto cualitativo en las políticas de ciudadanía de la Unión Europea, donde se provoca el despojo de la ciudadanía de algunos - aquellas vidas insignificantes - y se extrae el estatuto jurídico de un sujeto en nombre, precisamente, de la seguridad nacional y de una política contradictoria de derechos humanos: "Estos lugares han sido pensados desde un inicio como espacios de excepción; como zonas de suspensión absoluta de la ley, como campos de concentración, zonas donde todo es posible justamente porque la ley está suspendida" (Link, 2009). Entonces el migrante es en la actualidad una figura extrema, que por su propia externalidad ayuda a ver lo que está detrás del estatuto mismo del ciudadano. La tercera tesis de este artículo deviene de estos argumentos y constituye su fuerza rectora, su medio preciso: se confirma en los migrantes la violencia como fundamento de la ley - tesis de la ley como violencia-.

Sin embargo, a los migrantes no sólo se les ilegaliza. Varios autores han subrayado que asistimos a una nueva era en la que las migraciones internacionales son intensas y múltiples. La era de los circuitos migrantes transnacionales (Rouse, 1989), el momento de las comunidades transnacionales (Kearney, 1996; Besserer, 1999b) o la época de la modernización desbordada (Appadurai, 2001) son algunas de las perspectivas que se han dibujado para explicar esto. Todas destacan el momento intenso de las actividades migrantes. Sumo un argumento más. A medida que los viajes, las migraciones y los flujos de personas se han tornado amplios y masivos, se han multiplicado las maneras y se han reinventado las arterias por las que transitan las violencias. A una macropolítica de las violencias en la migración se le añade la proliferación de micropolíticas de las violencias en los desplazamientos y en los lugares de llegada.

Esto se explica en parte porque, además de que viven procesos constantes de ilegalización, a partir de septiembre de 2001 los migrantes padecen de manera constante los efectos de su criminalización. La era del terror significa que estamos ante una política global que dibuja y sanciona nuevas peligrosidades, y los migrantes son siempre presumiblemente criminales, personas de las cuales se debe sospechar. Al estudiar el cambio legal y político en la modernidad, Foucault concluye que la peligrosidad se ha vuelto central y supone ver al hombre no por sus actos sino por la posibilidad que tiene de llevarlos a cabo: "Toda la penalidad del siglo xix pasa a ser un control, no tanto sobre si lo que hacen los individuos está de acuerdo o no con la ley, sino más bien sobre lo que pueden hacer, son capaces de hacer, están dispuestos a hacer o están a punto de hacer" (Foucault, 2008: 101-102). 
De esto desprendo la cuarta tesis - tesis de la intensidad y la multiplicidad de las violencias en la migración-: se confirma la economía política de la seguridad como eje de las violencias y vulnerabilidades de los migrantes. La multiplicidad y la intensidad de los fenómenos migratorios van acompañadas de su opuesto, es decir, la propia singularidad de sus expresiones. Si lo pensamos con detenimiento, a pesar de la enorme variedad de signos que definen a las migraciones, mucho de su devenir se explica por la relación constante que tienen con el trabajo, la relación entre los cuerpos y la labor. Marx fue el primero en insistir en la dimensión fundamental de la acumulación originaria del capital en la economía de los cuerpos, como generador de la riqueza. La base de la economía es el trabajo - en lo cual coincidían neoclásicos y el propio Marx-, pero el trabajo se ejerce por medio de los cuerpos, a través de lo sensible del trabajo, por medio del cansancio y de la pura fuerza de trabajo que es siempre desplegada como plus trabajo que genera la ganancia.

Esta ontología de los cuerpos y el trabajo en Marx me permiten enlazar las vidas de los migrantes como vidas siempre en busca del trabajo. Ellos viajan a donde hay trabajo. El migrante desea el trabajo y es su primer deseo. Pero ese trabajo es casi siempre precario y en cuanto tal, forma de violencia constitutiva de lo social. Puedo decir a este respecto que el capitalismo - más precisamente el tardocapitalismo- es una gran máquina productora de trabajo precario, por tanto, trabajo violento. Los migrantes conforman ese apéndice de las máquinas capitalistas de formación del trabajo precario, como ha dicho Marx:

El obrero es más pobre cuanta más riqueza produce, cuanto más crece su producción en potencia y en volumen. El trabajador se convierte en una mercancía tanto más barata cuantas más mercancías produce. La desvalorización del mundo humano crece en razón directa de la valorización del mundo de las cosas. El trabajo no sólo produce mercancías: se produce también a sí mismo y al obrero como mercancía, y justamente en la proporción en que produce mercancías en general (Marx, 2001: 17).

La quinta tesis en este trabajo es sobre la economía política de los cuerpos migrantes: se confirma entonces la migración como una fórmula actualizada de administración del trabajo precario y de administración de los cuerpos migrantes. Las tesis anteriores me permiten caracterizar la condición y posición actual de los migrantes. Estas tesis funcionan y se producen todo el tiempo de forma rutinaria. Su cotidianidad provoca desplazamientos infinitesimales por donde transitan los migrantes y donde los acompañan las violencias. Como esto ocurre en todas partes y todo el tiempo, se produce la capacidad perversa por medio de la cual la expresión de las políticas y las violencias en la migración se tornan invisibles. Su cotidianidad, su enorme normalidad, el ser-parte-de nuestras experiencias de todos los días, provoca que sus fenómenos devengan en apenas perceptibles.

Hemos entrado en la época del terror, justo al momento paradójico que implica que cuantas más violencias viven los migrantes menos los vemos. Cuando aumenta con mayor crudeza su devenir violento, cuanto más se tornan en imágenes borrosas para nosotros. El momento fantasmagórico anunciado por Benjamin (2004), en el que el hombre deambula somnoliento y alienado frente al poder estético y político de las mercancías, se ha transformado en un momento migrante donde el indocumentado es fantasma de sí mismo y espectro de lo social. La última tesis que quiero plantear es la de la fantasmagoría de los migrantes: se confirma entonces la naturalización de su estatus y su perenne condición de precariedad y vida violenta.

En mi opinión, estas tesis pueden ayudar a explicar en gran parte la relación primaria enunciada al inicio, relación indisoluble entre migración, 
política y violencia. Las tesis no explican el todo, precisamente por la magnitud y amplitud del fenómeno. Reconozco una deuda con los estudios que dan testimonio de los éxitos de algunos migrantes, los logros de clubes y organizaciones transnacionales. Pero he querido detenerme en estas dimensiones violentas de la política de las migraciones contemporáneas porque me parece que son necesarias estas lecturas desde un academicismo que pretenda ir más allá de toda especulación escolástica y que quiera responder, en parte, al terror y al horror de cientos de historias ocultas que escuchamos a diario y para las cuales se requieren esfuerzos de interpretación. Con estas tesis, además de las viñetas que expondré a continuación, espero arribar a algunas conclusiones que den respuestas a las preguntas planteadas al inicio.

\section{PUEBLOS Y FAMILIAS EN LA MIGRACIÓN A ESTADOS UNIDOS. EL CASO DE LOS MIXTECOS EN CALIFORNIA}

El método etnográfico de trabajo en antropología puede ser muy útil para observar cómo operan las tesis anunciadas. En esta disciplina solemos decir que la antropología "mira en pequeño para pensar en grande". Durante años he seguido el devenir migrante de un pueblo oaxaqueño en California. ${ }^{5}$ Los migrantes mixtecos - ñu saavi - de San Juan Mixtepec llegaron a California en la década de 1970. Habían cruzado la frontera después de haberse insertado en la economía del tomate en el noroeste de México, misma que forma parte de una cadena global de mercancía que enlaza la economía de ambos países. Como muchos informantes plantearon con insistencia, las migraciones de los mixtecos nunca fueron espontáneas o guiadas por el azar, al contrario, siempre estuvieron inscritas en una lógica de economía política muy precisa:
Nosotros, hombres, mujeres y niños, salimos en busca de la vida, forzados en busca de sobrevivencia, no somos turistas que de repente se nos ocurrió ir a Chiapas porque Chiapas es muy bonito, o ir a Sinaloa o a Mazatlán o a las playas, o a los centros turísticos. Nosotros fuimos y conocimos los campos cafetaleros, cañeros, viñedos, de hortalizas y cruzamos el desierto, y trabajamos para sobrevivir con nuestras familias (entrevista con Moisés Cruz Sánchez, líder mixteco, diciembre de 2004).

Precariedad y urgencia por tener un empleo fueron las fuerzas básicas de lo social que dieron pauta para que este pueblo indígena llegase a conformar una de las principales diásporas de mexicanos en Estados Unidos y la primera minoría étnica, por ejemplo, en California (Huízar y Cerda, 2004). Varios estudios confirman estos dos aspectos. Por una parte el vínculo constante de estos grandes movimientos de población con el trabajo, y por otra su carácter histórico, lo cual la ha hecho permanente en el tiempo. Leticia Méndez y Mercado, en su clásico estudio sobre las migraciones de este pueblo, dice:

Así, campesinos e indígenas perdieron de manera paulatina sus tierras y se vieron obligados a trabajar en las tierras de otros [...] si bien el empobrecimiento de la tierra, la raquítica productividad y las carencias presionaron —y aún lo hacen-a sus habitantes a abandonar las tierras que les pertenecían, la realidad más determinante está en el mecanismo de extracción de población y, por ende, una transformación radical de la estructura económica del país por la generalización de un sistema económico y las exigencias que éste provoca. Por tanto [...] los indígenas están acosados por una sola

$5 \quad$ El material de investigación de esta parte proviene de mis trabajos con un pueblo migrante en sus desplazamientos a lo largo de los años 2003 al 2011. 
alternativa: integrarse como mano de obra en los niveles ocupacionales de una nueva economía (Méndez, 1985: 11-12).

Esta nueva economía de la que nos habla la antropóloga es la que observé en mi estudio sobre la justicia en los procesos migratorios (Castro, 2009). Fui descubriendo la intrincada relación que existe, a partir de las migraciones internacionales que mueven toda la estructura social del pueblo, entre una economía política determinada y lo que podríamos denominar como “economía emocional" o "libidinal” muy específica. ${ }^{6}$

La economía política que los afecta consiste en una serie de mecanismos estructurales por medio de los cuales los mixtecos viven en condiciones transnacionales de injusticia, casi siempre en medio de campos económicos en los que abunda la precariedad y la ausencia de derechos laborales. Las situaciones estructurales de precariedad e injusticia, aunque diferentes del todo en ambos países y contextos, terminan por confirmar las condiciones de vulnerabilidad de los migrantes en ambos lados de la frontera. Una especie de injusticia y precariedad transnacional emerge a partir del estudio de los pueblos migrantes, cuestión que se suma a su carácter histórico, pues como señalan varios estudios:

Las comunidades de campesinos mixtecos han servido como una reserva laboral para una larga serie de amos tras los siglos, desde los antiguos caciques de hace 500 años hasta los intereses agrícolas mexicanos y estadounidenses de hoy. Pero el patrón básico siempre ha sido el mismo: una apropiación del trabajo servil barato, subsidiado por el trabajo doméstico (Edinger, 2004: 32).

La lista de evidencias que comprueba el peso de las variables de economía política en los rumbos y los destinos de la migración podría ser enorme. Sin embargo, quizás sea suficiente con escuchar lo que los mismos mixtecos dicen acerca de esto:
Muchos de nosotros hemos vivido una vida dura, hemos trabajado desde una temprana edad, hemos sido abusados de los rancheros, hemos sido discriminados en nuestras propias tierras, hemos sido explotados en todo el sentido de la palabra y tenemos muchas cosas que relatar para que el mundo vea cómo se nos trata en nuestras tierras y en nuestro continente (V. S., opinión vertida en el Grupo Yahoo Mixtepec, 8 de enero de 2008).

En cuanto a la economía emocional, el segundo elemento constitutivo de los procesos migratorios, incluyo aquí todos esos sentimientos culturales (Benjamin, 2007) o regímenes sentimentales (Besserer, 1999a) que subrayan la manera en que el rechazo, la discriminación y el odio racial y de clase se constituyen como las fuerzas fundamentales que modelan los fenómenos asociados a la migración internacional. En lugar de verlos como cosas aparte que no merecen ser estudiadas, he destacado en otro trabajo la importancia de la investigación de la subjetividad migrante como parte de un corpus de fuerzas y fenómenos que pueden explicar por qué las cosas funcionan de este modo y no de otro (Castro, 2012).

En el citado trabajo presenté el caso de dos hermanos mixtecos, uno de ellos menor de edad, que murieron intoxicados mientras trabajaban en un túnel de 8 pies en el Community Recycling and Resources Co. en California en 2011. Su muerte despertó la indignación y el reclamo de la comunidad de mixtecos de ese estado, quienes protagonizaron un inusual activismo en las redes y en las páginas que convocan a los mixtecos en Estados Unidos. Denunciaban que eran tratados como

Foucault fue uno de los primeros pensadores que quisieron resaltar el aspecto emocional de la economía e intentó con ello superar la dicotomía que divide radicalmente la subjetividad de la objetividad, la idealidad y la materialidad. Véase, por ejemplo, Foucault (2006). 


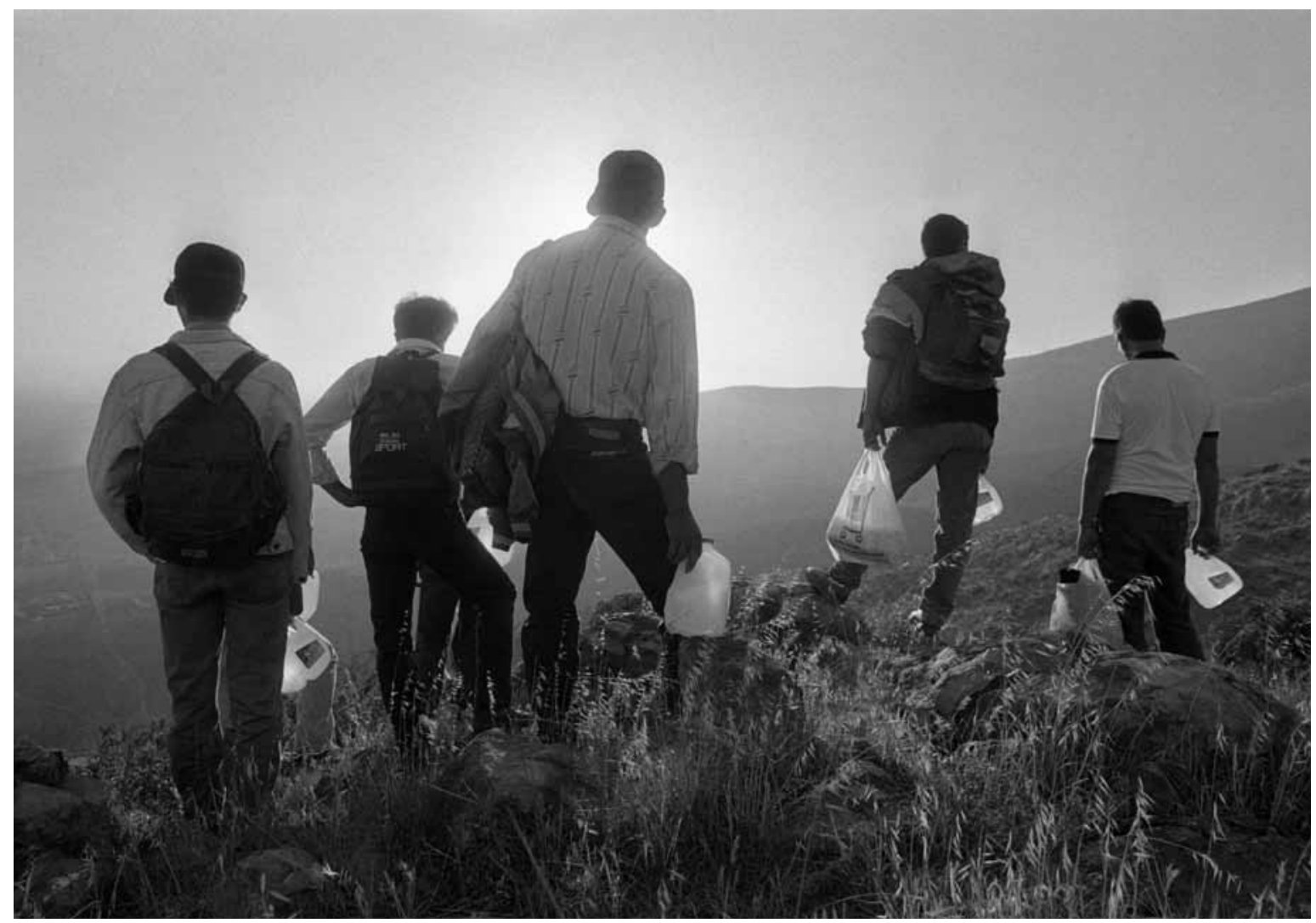

Elsa Medina Castro • Nido de las Águilas, Tijuana, B. C., 1996, Frontera México/eua.

criminales y que en este caso E., el hermano mayor, había metido a su hermano con una "mica chueca" - papeles falsos-, en la que se indicaba que tenía 30 años de edad:

ambos eran originarios de Oaxaca. Para cuando los trabajadores fueron sacados del túnel ambos no estaban respirando porque habían aspirado tóxicos. Ese mismo día por la noche A. R. de 16 años de edad falleció en el hospital local de Bakersfield. Y hoy por la mañana el hermano de A. R. de 21 años, también iba a ser desconectado ya que sus células se cocieron con el tóxico y le dañaron el cerebro (información publicada en el sitio de mixtecos de San Juan Mixtepec, <mixtepec.blogspot.com>, octubre de 2011).
La compañía, decían en los chats, no se preocupó por averiguar la verdadera edad del muchacho porque así trabajan, les sirve que sean indocumentados porque aprovechan al máximo su situación vulnerable. Es comprensible observar otras tendencias en esta caracterización. Sólo por mencionar algunas, hay autores que han destacado los procesos, por ejemplo, de "mexicanización de los pueblos y valles de California" (Palerm, 1997 y 1998), es decir, amplios procesos de cambio demográfico en los que mexicanos son clave en la estructuración económica, cultural y política de muchos sitios en Estados Unidos. Sin desconocer estos procesos, en este trabajo trato de resaltar los otros impulsos en la migración internacional, aquellos que hablan de las dificultades que, en mi opinión, han adquirido una posición 
dramática a partir de los giros de seguridad que se han implantado en todo el mundo.

Los mixtecos llegaron a California a reemplazar la mano de obra que mexicanos del centro occidente dejaban para acceder a otros espacios en Estados Unidos. A su vez, aquéllos habían llegado al "estado dorado" para sustituir el trabajo que estadounidenses del medio oeste y chicanos habían hecho antes, y antes de ellos, japoneses, y antes de éstos, chinos. El reemplazo étnico de la fuerza de trabajo (Kearney, 1996; Durand, 2011), el movimiento de ejércitos de reserva de trabajadores, ha sido la tónica en el estado donde la agricultura capitalista se ha levantado como la más importante de toda esa nación. La regla económica no escrita en esa economía ha sido: cada vez que un grupo cultural logra el reconocimiento de ciertos derechos en el trabajo y en su presencia en Estados Unidos es estigmatizado y presentado como enemigo cultural, ${ }^{7}$ como amenaza al modo de vida americano, hasta producir su exclusión progresiva.

Como propusieron estudios clásicos en California, una vez que ese estado se incorpora a la Unión Americana no acepta la esclavitud, sin embargo encuentra en el uso de la fuerza de trabajo inmigrante la fórmula para explotar a gente desesperada como si fuese, lisa y llanamente, esclavitud (Goldschmidt, 1947; McWilliams, 1935). La migración a escala ampliada puede definirse, de acuerdo con esta argumentación, como la gran productora de una clase obrera deslocalizada, como señalan Berger y Mohr (2011), una clase fragmentada, que sufre condiciones de trabajo tedioso, rutinario e incluso trabajo esclavo. Los migrantes satisfacen la escasez de mano de obra e inhiben la mejora de las condiciones de salario de la población general de los países. Muchos de los migrantes mixtecos en Estados Unidos se transformaron en esos obreros ideales para la nueva economía: de bajos salarios y casi sin ningún derecho laboral. Como lo previera Marx, el trabajo produce maravillas, pero también privaciones: "Produce palacios, pero para el trabajador chozas. Produce belleza, pero deformidades para el trabajador. Sustituye el trabajo por máquinas, pero arroja una parte de los trabajadores a un trabajo bárbaro, y convierte en máquinas a la otra parte" (Marx, 2001: 18).

Los primeros años no fueron fáciles para los migrantes mixtecos en Estados Unidos, pero tampoco lo son ahora, en especial a partir de la emergencia de los paradigmas de securitización después de 2001. Cuando visité a mis amigos mixtecos en California en 2011, que han ido "echando raíces allí", me sorprendió que muchos de ellos estaban haciendo todo lo posible para recibir a sus parientes que venían huyendo de la crisis económica y de la ola de persecuciones en Arizona. La Ley sB 1070 de Arizona había aprobado que cualquier policía o autoridad pudiera pedir papeles ante la "sospecha razonable" de estar frente a un migrante indocumentado.

Los mixtecos de Arizona me dijeron que la ley hacía legal la discriminación y que mientras ellos siguieran representando esa amenaza lo mejor era ir a donde estaban sus parientes en California. Pero ahí las cosas tampoco estaban del todo solucionadas. Meses más tarde de mi visita, una parte de la comunidad de mixtecos logró que en el Distrito Escolar de Oxnard, al noroeste de Los Ángeles, se eliminara y se sancionara el uso de la palabra "oaxaquita" con el que los mexicanos no indígenas molestan y discriminan a sus compatriotas. ${ }^{8}$ La disposición del

7 Ejemplos de esto abundan en California. Por mencionar uno, Lloyd Fisher explica en su clásico estudio cómo después de que los inmigrantes chinos conquistaron derechos laborales en el estado y en la medida en que adquirían cierta independencia económica, posterior a 1870, se extendió la idea de que eran peligrosos y debían ser excluidos, cuestión conocida como The Yellow Peril. La situación se concreta en 1892, cuando se decreta la prohibición de que entren más chinos al país por medio de la llamada Geary Act (Fisher, 1953: 24). La campaña se llamó "Don't call me little Oaxacan” y concentraba los esfuerzos de miembros de este pueblo que habían sido despreciados y rechazados históricamente por sus compatriotas mexicanos provenientes de estados con menos población indígena. 
Distrito Escolar, como quedaba enunciada en el reportaje publicado en Los Angeles Times el 28 de mayo de 2012, reconocía la importancia numérica de los mixtecos en la agricultura californiana, donde $80 \%$ del universo total de trabajadores de esta industria era mano de obra indocumentada y 30\% era de origen mixteco.

Los mixtecos en Estados Unidos no podían esperar que sólo fuesen las leyes las que actuaran en su contra. No tenían que ir tan lejos. Ha sido suficiente observar cómo sus mismos compatriotas han jugado un papel clave en la economía emocional del desprecio. Racismo y rechazo han actuado juntos, como también lo ha hecho aquella economía estructurada en torno al cansancio, al trabajo precario, a la escasez de derechos laborales y a la criminalización. ${ }^{9}$

Mirado de esta manera, el migrante transforma su figura en ilustradora del capitalismo actual. Riqueza y pobreza como dos cosas que trabajan juntas. Hiper-producción de mercancías y des-producción de vidas humanas. La fantasmagoría que representa la sociedad actual queda así bien explicada: un migrante es un fantasma que se parece cada vez más a esa mercancía, consumible y desechable. En cualquier caso, es una mercancía bien preparada para ese devenir laboral tan propio del funcionamiento de las cosas hoy en día.

\section{MIGRACIÓN EN TRÁNSITO, MIGRACIÓN INDOCUMENTADA: EL PÉNDULO ENTRE EL FETICHISMO DE LA LEY Y LAS CRISIS HUMANITARIAS}

Son ya muchos los organismos nacionales e internacionales que al observar el paso de los migrantes por México hablan de su situación en términos de una crisis humanitaria. ${ }^{10}$ De esto nos hablan los 20000 migrantes secuestrados al año en México. Sumado a ello, un sinnúmero de actividades legales, ilegales y cuasi legales producen ganancias económicas superiores a los 6500 millones de dólares que van a parar al esponjoso concepto de "crimen organizado". ${ }^{11} \mathrm{Se}$ debe hablar, en este sentido y con todas sus letras, de una verdadera economía política de administración de vidas humanas. Recuerdo que en 2010 asistí a una conferencia para comentar una serie de cuatro documentales cortos sobre los migrantes en tránsito. ${ }^{12}$ En una mesa integrada por tres especialistas en el tema, el investigador A. A. ${ }^{13}$ contó que en su institución habían tenido reuniones con personal de gobierno para hablar de la minuta para una nueva ley migratoria en México. El tema era sensible para México en ese momento. De eso hablaban los documentales y la mayoría de los periódicos de circulación nacional, en especial porque casi todos estaban impactados por el hallazgos de más de 190 cuerpos en Tamaulipas, lo cual ponía a la violencia y al crimen en la frontera norte sobre la mesa de discusión en un paralelo de la memoria de muchos que recordaba a los 72 migrantes muertos. ${ }^{14}$

9 La perversidad del asunto, la exclusión entre personas que comparten similares condiciones de precariedad y abandono, ha sido observada en innumerables trabajos. De Gramsci a Fanon, pasando por muchos autores críticos que trataron de comprender el comportamiento de subalternos o colonizados, respectivamente. Se ha generado a partir de ello una prolífica e importante producción intelectual y política (Gramsci, 1999; Fanon, 2007).

10 Sólo por mencionar algunos, se han manifestado en ese sentido la Comisión Nacional de Derechos Humanos, la Subprocuraduría de Derechos Humanos de la Procuraduría General de la República, Amnistía Internacional y Human Rights Watch.

11 Para la primera cifra, Informe de 2010 de la Comisión Nacional de Derechos Humanos y para la segunda, Diario de los Debates del 29 de junio de 2011 del H. Congreso de la Unión de México.

12 Me refiero a Los invisibles, documental realizado por Marc Silver y Gael García Bernal (Amnistía Internacional, 2010).

13 Para proteger la identidad del investigador y su institución prefiero apuntar las iniciales.

14 Me refiero a los hechos ocurridos en el municipio de San Fernando, en el norteño estado de Tamaulipas, donde se encontraron 193 muertos en fosas clandestinas el 6 de abril de 2011. En agosto de 2010, en el mismo municipio fueron hallados los cuerpos de 72 personas asesinadas. Esta zona se encuentra en la ruta migratoria por donde mexicanos y centroamericanos transitan rumbo a Estados Unidos. 
El investigador del Centro de Investigación y Docencia Económicas (CIDE) narró cómo en una de esas reuniones preguntaron a los representantes del Instituto Nacional de Migración (INM) qué estaban haciendo para combatir los secuestros de migrantes. La respuesta de los funcionarios fue práctica: "Nada", porque "ése es un asunto de la policía". La respuesta es peculiar por varios aspectos: porque la credibilidad de las acciones de la policía y de varios cuerpos de uniformados en México está cada vez más en cuestión, porque refleja el tipo de acciones que el Estado ha emprendido en materia migratoria y porque pareciera que vivimos una suerte de fragmentación de aquello que podemos concebir como Estado y como procuración de justicia, lo que resulta en un espectáculo del horror.

Jean y John Comaroff presentaron un análisis sugerente sobre lo que parece caracterizar al mundo actual. Por una parte, una tendencia hacia la descripción del mundo subdesarrollado como envuelto en una inmensa epopeya de anarquía y violencia - en la que se torna cada vez más difícil diferenciar entre regímenes políticos de poder y crimen organizado - y, por otra, la proliferación y el apego a la ley, lo legal y lo jurídico para resolver las situaciones, la transformación de la ley en un verdadero fetiche:

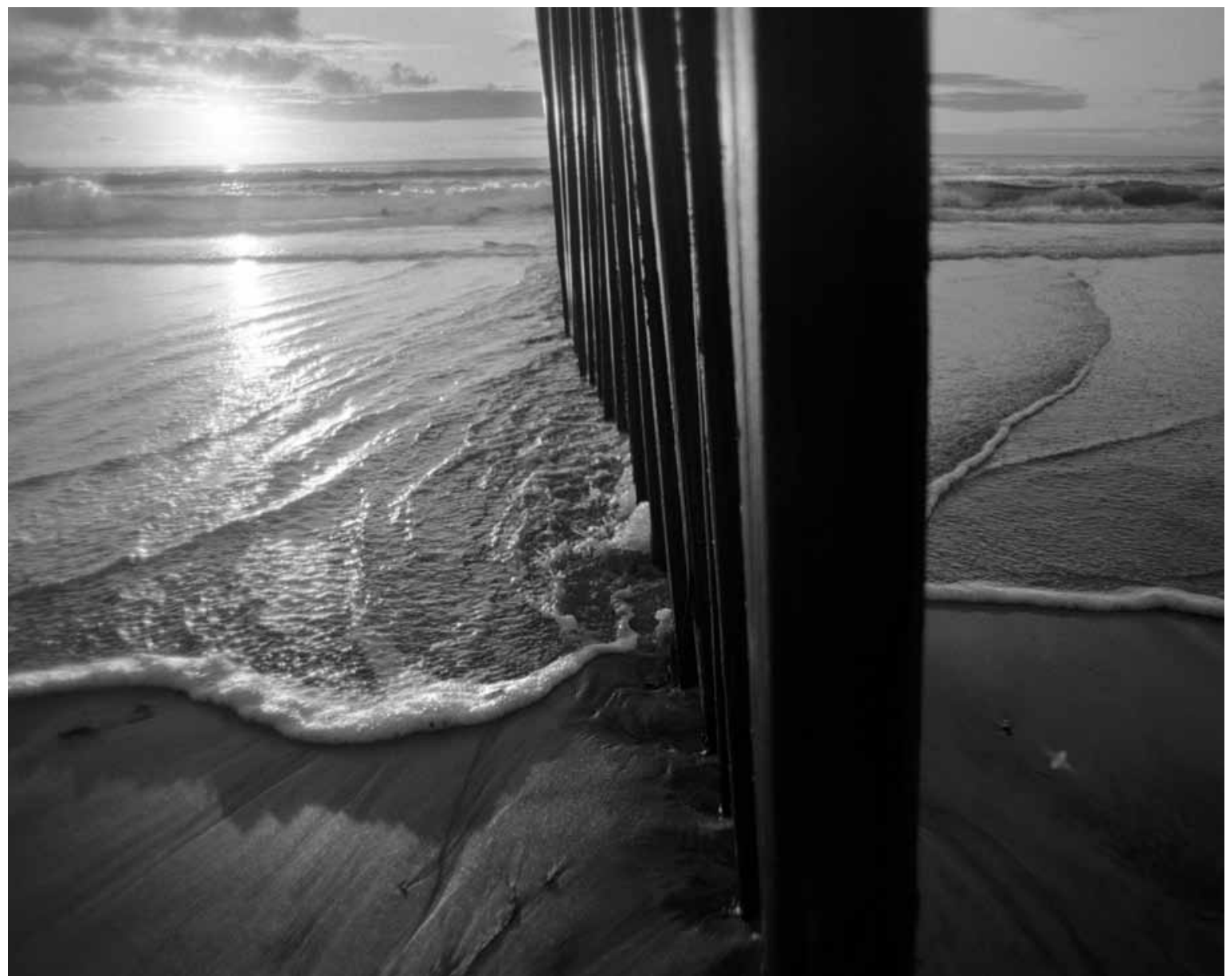

Elsa Medina Castro • Playas de Tijuana, B. C., 2007, Frontera México/Eua. 
Sin cesar se redactan nuevas constituciones, se hacen llamamientos a los derechos, se reinventan democracias de procedimientos y se presentan demandas por injusticias. Y sin cesar también, los gobiernos, los grupos de composición diversa y las coaliciones de intereses recurren al sistema jurídico para resolver sus diferencias (Comaroff y Comaroff, 2009: 12).

Al observar el tránsito de los migrantes por México o la migración indocumentada en Estados Unidos, esta reflexión de los antropólogos sudafricanos cobra relevancia. El fetichismo de la ley parece crecer en la medida en que aumenta y se modifica la cartografía del desorden, de lo que resulta que la ley y la violencia parecen ser complementarias. El debate y la producción de leyes sobre la inmigración en México y Estados Unidos resulta en una serie de campos y fuerzas ilustradoras de las paradojas presentes y de las tesis enunciadas en este trabajo. Todas parecen confirmar la antinomia fundamental que he caracterizado a partir de la producción legal para la protección y la misma producción para la criminalización. Por ejemplo, en 2010, cuando la situación de los migrantes que pasaban por México parecía cobrar inusitados niveles de violencia y crimen, en Arizona se aprobaba la Ley Arizona SB 1070, la cual dice en su encabezado: "Ley sB 1070. Para toda detención o arresto legal hechos por un oficial de un departamento de policía en la que exista la sospecha razonable de que la persona es un extranjero y se encuentra ilegalmente en Estados Unidos".

Para justificar esta ley, la gobernadora del estado Jan Brewer mencionaba con insistencia que el crimen y la violencia asociados a los migrantes llegaron a ser un asunto crítico para su administración. La idea de que la migración y el delito eran piezas complementarias y que trabajaban juntas estaba en la base de toda esta producción legal, cuestión muy arraigada en diversos sectores de la sociedad estadounidense, a pesar de que muchos estudios confirman lo contrario. ${ }^{15}$ Kris Kobach, un abogado de Kansas que estuvo detrás de la Ley de Arizona, conocida entre los migrantes como "Ley del Odio", como miembro de la Federation for American Immmigration Reform (FAIR), sostuvo: "Quiero hablarles de la teoría detrás de lo que Arizona está haciendo. La idea es muy simple. Si haces más difícil que la ley se quebrante, la gente comienza a obedecer la ley. Aumentas la aplicación de las leyes y la gente se deporta sola" (Dávalos y Carbajal, 2011). Efectivamente, la dura ley migratoria estaba provocando que la gente se deportase sola, cuestión que ya referí en mi encuentro con mixtecos en California.

La ley provocó una gran discusión en muchos sectores hasta que en abril de 2011 el presidente Obama logró que la Corte de Apelaciones de la nación quitara los fragmentos más polémicos de la misma. Desde ese momento el debate en Estados Unidos se trasladó al Congreso sin que hasta ahora se hayan podido cambiar las leyes de inmigración en el país. En 1986 las leyes en Estados Unidos se modificaron para legalizar a tres millones de inmigrantes indocumentados. Hoy la discusión en el Congreso es sobre la situación de unos $11 \mathrm{mi}-$ llones de extranjeros sin documentos migratorios. Por ahora no se ve una posible solución, en especial después de que en febrero de 2014 John Boehner, presidente del cuerpo legislativo, reconoció que la aprobación de un cambio en las leyes migratorias no sucedería este año.

La visión de seguridad sigue predominando en la discusión legislativa, mientras el presidente

Por ejemplo, Wright y Benson (2010) mencionan la existencia de una "paradoja inmigrante" o "paradoja latina" según la cual, y contrario al estereotipo que supone que los inmigrantes provocan el aumento de los crímenes en las calles, en los barrios de inmigrantes los índices de violencia son menores. Ellos explican en su estudio que esto se debe a los valores culturales de los migrantes y a sus fuertes lazos y redes de apoyo, los cuales empujan a un índice más bien bajo del crimen. 
Obama ha insistido en que su prioridad es que se apruebe una ley para 2014. Una paradoja importante es que a pesar de la retórica de la administración en la Casa Blanca, el gobierno de este presidente es el que más deportaciones ha hecho en la historia reciente del país. En cinco años de su gobierno se cuentan dos millones de deportaciones realizadas, aproximadamente 400000 al año (Contacto Magazi$n e$, s. f.). Es importante recordar que las paradojas se multiplican precisamente porque la ley no es sólo la ley. Es decir, discutir y debatir sobre las leyes, con sus consecuentes efectos concretos, produce un desplazamiento de la ley hacia sitios insospechados de la sociedad. En términos de Foucault, para quien la ley resultaba ser un lugar privilegiado para observar lo político, en la actualidad no es la única que cumple funciones de justicia, una serie de poderes laterales lo hacen y, aunque no son judiciales en sí, terminan cumpliendo funciones que sí lo son: "Afuera de la justicia estatizada nacen procesos de control que acaban siendo el verdadero contenido de la práctica penal" (Foucault, 2008: 106).

En el caso de la migración indocumentada en Estados Unidos, esto se traduce en la proliferación de múltiples mecanismos de control y vigilancia, que resulta en la constante vulnerabilidad de los migrantes. Por ejemplo, con el impulso para discutir un cambio legal en Estados Unidos, el presidente Obama ha encargado al Congreso el aumento de recursos para la frontera con México. Esto supone mayor número de soldados de la Guardia Nacional, apoyo para que la Patrulla Fronteriza reclute e incremente el número de agentes, la creación de una Oficina Federal de Informaciones con énfasis en la frontera sur, así como la participación in situ de la Drug Enforcement Administration, la Bureau of Alcohol, Tobacco, Firearms and Explosives y de Immigration and Customs Enforcement (Incedes y Sin Fronteras, 2011). La securitización de la política migratoria sumada a la proliferación de leyes y reglamentos de todo tipo — la fetichización de la ley_ producen a fin de cuentas que los eventos en Estados Unidos estén ligados a lo que ocurre en México. Todas las medidas señaladas afectan los flujos migratorios y la situación de los derechos humanos de los migrantes, así como las respectivas presiones en la frontera norte y sur de México (Incedes y Sin Fronteras, 2011).

Lo que ha ocurrido en Arizona y en Estados Unidos en materia de migración permite cuestionar lo que ocurre en México. Aunque las discusiones legislativas en este país estuvieron plagadas de referencias a la Ley Arizona como ejemplo del racismo y la exclusión que viven los connacionales allá, poco se discutió sobre la manera en ocurren las cosas acá. Por ejemplo, aunque en las discusiones parlamentarias se mencionó muchas veces la "sospecha razonable" como un aspecto delicado de esa ley, en las críticas señaladas por organizaciones de protección a migrantes se insistió poco en que en México la “identificación y verificación migratoria basada en perfiles étnicos, raciales o nacionales lleva muchos años realizando sus actividades migratorias con base en ellos" (Incedes y Sin Fronteras, 2011: 423).

Es más, como han indicado algunas investigaciones al respecto, en México desde la primera Ley de Extranjería y Naturalización promulgada durante el gobierno de Porfirio Díaz en 1886, que buscaba el arribo de europeos católicos al país, la política migratoria dividió a los inmigrantes en dos clases de personas: los migrantes "benéficos" que ayudarían al desarrollo de México y los migrantes "perniciosos" que sólo vienen a provocar daño (Yarrington, 2013: 35). En el estudio comparativo de las leyes y el comportamiento migratorio en México y varios países centroamericanos la organización Sin Fronteras insiste en estos rasgos ambiguos de las legislaciones. Todas las constituciones de estos países incorporan el reconocimiento amplio de los derechos humanos y garantizan la universalidad de su goce (Yarrington, 2013: 41). Pero al mismo tiempo, todas las legislaciones establecen restricciones para el ejercicio de estos derechos a las personas extranjeras. 
De acuerdo con el "Informe sobre las migraciones en el mundo 2010” (оIM, 2010), en el mundo hay más de 200 millones de personas definidas como migrantes internacionales. México aparece como el lugar de tránsito con el mayor volumen de movimiento de población que atraviesa su territorio con unos 10 millones de personas cada cinco años. La situación de vulnerabilidad y violencia que viven los migrantes en México se vio afectada después de 2001 porque a manera de espejo o reflejo, la política migratoria se construye en México mirando hacia Estados Unidos y con referencia a ese país, es decir, también sobre una lógica de seguridad.

Por ejemplo, en México se presenta el proyecto Propuesta de Política Migratoria Integral en la Frontera Sur de México 2005, que proviene a su vez del Plan Reforzamiento de la Frontera Sur del País o "Plan Frontera Sur", vigente de 2001 a principios de 2003, cuando fue sustituido por el proyecto "Fortalecimiento de las Delegaciones Regionales de la Frontera Sur". Podemos decir que el "Plan Frontera Sur", que arranca en 2001, marca una nueva faceta en la manera en que el país va a incorporar las dimensiones de securitización en materia migratoria: "Claramente comienza a fusionar elementos de delincuencia organizada y seguridad con las acciones a instrumentar en materia de flujos de personas irregulares en el país" (Incedes y Sin Fronteras, 2011: 388).

Como reconocen organizaciones de defensa de los derechos de los migrantes, todas las medidas tienden a criminalizar y a catalogar a la migración indocumentada como una amenaza. En 2005, según informes de estos organismos, el tema migratorio es incorporado en la Agenda de Seguridad Nacional e incluso el INM pasa a formar parte del Consejo de Seguridad Nacional:

Medidas como la Iniciativa Mérida, la Operación de sellamiento de las fronteras contra el narcotráfico y el Plan Centinela contra el terrorismo, además de dotar al Instituto de mayores recursos [...] son estrategias que tienen una utilidad e impacto en la política de control y vigilancia de los flujos de migrantes (Incedes y Sin Fronteras, 2011: 389).

En 2011 se aprueba una nueva Ley de Migración en México, que precisamente confirmará la ambigüedad de una política migratoria que a la vez que busca la protección de los derechos humanos de los migrantes, insiste en su criminalización. El primer artículo de la Ley es especialmente claro en este punto:

Artículo 1. Las disposiciones de esta Ley son de orden público y de observancia general en toda la República y tienen por objeto regular lo relativo al ingreso y salida de mexicanos y extranjeros al territorio de los Estados Unidos Mexicanos y el tránsito y la estancia de los extranjeros en el mismo, en un marco de respeto, protección y salvaguarda de los derechos humanos, de contribución al desarrollo nacional, así como de preservación de la soberanía y de la seguridad nacionales.

¿Es posible garantizar los derechos humanos de los migrantes a la vez que procurar la seguridad del país y de las fronteras nacionales? ¿Acaso no estamos frente a una antinomia irrepresentable? En ningún caso el objetivo de la Ley es evitar o disminuir la vulnerabilidad de los migrantes. Al contrario, ahora ellos están en una precariedad mayor que antes. En la investigación de Yarrington sobre la interacción de extranjeros indocumentados con el INM, se hace evidente que ahora el Instituto tiene mayores facultades de control, esto hace los procesos de legalización más complejos y sujetos a la discrecionalidad de los funcionarios (Yarrington, 2013). ${ }^{16}$

Hay muchos elementos en este sentido: cambian las definiciones sobre qué es una familia y qué miembros de la misma pueden legalizarse. Los mecanismos para comprobar un permiso de trabajo son más complejos y el ınm tiene ahora mecanismos de verificación más amplios. 


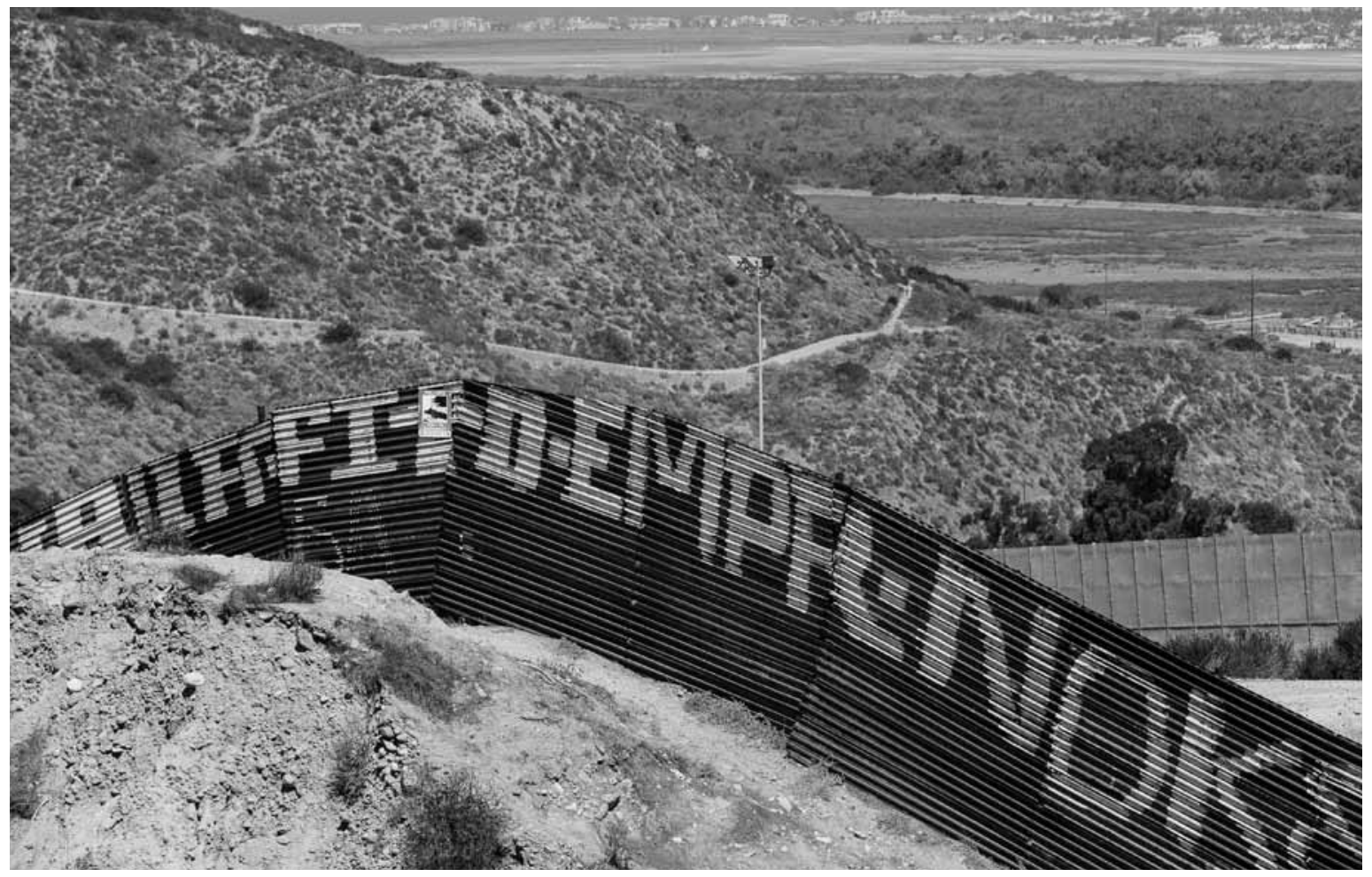

Prometeo Lucero • Muro fronterizo, Tijuana.

El endurecimiento de la ley, además, de acuerdo con el informe de Sin Fronteras, no favorece la transparencia gubernamental en materia migratoria y deja a los migrantes expuestos a mayor incertidumbre y precariedad, de manera que son presa fácil del crimen organizado y de las múltiples violaciones a sus derechos fundamentales, como lo reflejan los casos mencionados (Incedes y Sin Fronteras, 2011: 390).

\section{Conclusiones y reflexiones finales}

En este trabajo el material y los argumentos presentados han dado respuesta a las preguntas planteadas en el inicio. Aunque la violencia y la política han jugado un rol "productivo" histórico en las vidas precarias de los migrantes, nos encontramos hoy atravesados por un paradigma de seguridad que precisamente produce inseguridad, una idea de orden que genera desórdenes por dondequiera, un estado de cosas que confirma con asombrosa certeza las tesis de Benjamin de que los Estados de excepción son la regla, que las excepciones son las que producen normalidad. Puedo ir aún más lejos en mi argumento. Lo que emerge a partir de la caída de las Torres Gemelas en Nueva York es su diferencia cualitativa con un momento anterior que es precisamente la perversidad del mundo contemporáneo, en el cual las leyes y la violencia trabajan juntas para construir un enemigo declarado, que se ajusta a la perfección con la experiencia migrante.

Como he insistido a lo largo de estas páginas, en consonancia con Agamben y su trabajo sobre los refugiados, los migrantes, los indocumentados, los clandestinos de todo tipo son ahora conceptos límite, no porque se encuentren fuera de 
la política, por el contrario, porque provocan que nos demos cuenta de la crisis radical de las categorías fundantes de la sociedad, el Estado y la cultura occidental (Benjamin, 2007: 170). El drama de los migrantes es un drama no porque lo podamos observar desde el teatro espectacular de su situación, al contrario, lo es porque con ellos nos vamos todos hasta reconocer la precaria composición del mundo que hemos construido, la triste humanidad que nos compromete a un vacío.

Las múltiples paradojas, las antinomias insalvables, la imposibilidad de representar esto en un curso coherente de la historia nos obliga a reconocer las debilidades del edificio social que hemos erigido. Toda política actual es una política que produce diferencias, que condena a unos a vidas a la sombra de la humanidad, como si apenas supiésemos que existen para nosotros. La perversidad de la política en clave de los migrantes, construida en nombre de su protección, lo que hace es garantizar su muerte. Toda política de defensa de la vida lleva implícita su opuesto, una política de muerte, lo que para Foucault se resume en la expresión paradójica que indica que en el mundo actual "las matanzas han llegado a ser vitales” (Foucault, 1978).

No hay fenómeno de relevancia internacional que escape a la doble tendencia que lo coloca en una única línea de significado; por una parte, una creciente superposición entre el ámbito de la política, o del derecho, y el de la vida; por la otra, un vínculo igualmente estrecho con la muerte (Esposito, 2011).

Quizá la esperanza radica, en este punto, en la misma radicalidad de la situación migrante. Más allá de esto, se pierde cualquier horizonte de presente y futuro para este mundo que no ha terminado nunca de quedar bien construido. $\mathbb{D}$

\section{Bibliografía}

Adamson, Fiona B., 2006, "Crossing Borders: International Migration and National Security”, en International Security, vol. 31, núm. 1, pp. 165-199. Agamben, Giorgio, 2006, Homo sacer. El poder soberano y la nuda vida, Pre-textos, Valencia.

Amnistía Internacional, 2010, Los invisibles, documental, realizado por Marc Silver y Gael García Bernal, Amnistía Internacional, México. Appadurai, Arjun, 2001, Modernidad desbordada. Dimensiones culturales de la globalización, Trilce, Buenos Aires.

Benjamin, Walter, 2004, Libro de los pasajes, Akal, Madrid.

—_, 2007, Para una crítica de la violencia, Terramar, Buenos Aires.

Berger, John y Jean Mohr, 2011, Un séptimo hombre, Sur+, Oaxaca.

Besserer, Federico, 1999a, "Sentimientos (in)apropiados de las mujeres migrantes: hacia una nueva ciudadanía", en Dalia Barrera y Cristina Oehmichen (eds.), Migración y relaciones de género en México, Instituto de Investigaciones Antropológicas-Universidad Nacional Autónoma de México, Grupo Interdisciplinario sobre Mujer, Trabajo y Pobreza, México.

—_, 1999b, "Estudios transnacionales y ciudadanía transnacional", en Gail Mummert (ed.), Fronteras fragmentadas, El Colegio de Michoacán, Zamora.

Bolaños, Bernardo, 2012, “Extraneus y extrarius. Las biopolíticas de la migración”, en Yerko Castro Neira (coord.), La migración y sus efectos en la cultura, Consejo Nacional para la Cultura y las Artes, México, pp. 21-41.

Castro Neira, Yerko, 2009, En la orilla de la justicia. Migración y justicia en los márgenes del Estado, Universidad Autónoma MetropolitanaIztapalapa, Juan Pablos, México.

__ 2012, "Racismo y subjetividad. Efectos del rechazo y el desprecio en el trabajo y en la identidad de los migrantes en Estados Unidos y México”, en Yerko Castro Neira (coord.), La migración y sus efectos en la cultura, Consejo Nacional para la Cultura y las Artes, México, pp. 135-155.

Comaroff, John y Jean Comaroff, 2009, Violencia y ley en la poscolonia: una reflexión sobre las complicidades norte-sur, Katz Editores, Madrid. 
Chebel d'Appollonia, Ariane, 2012, Frontiers of Fear: Immigration and Insecurity in the United States, Cornell University Press, Ithaca.

Comisión Nacional de los Derechos Humanos (CNDH), 2011, "Informe especial sobre secuestro de migrantes en México. 22 de febrero de 2011 ", Comisión Nacional de los Derechos Humanos, México.

Contacto Magazine, s. f., "Boehner: no habrá reforma migratoria en 2014", en línea: <http://www.contactomagazine.com/articulos/boehnerreformamigratoria0214.htm\#.UOHiMMezgnU>, consultado en marzo de 2014.

Dávalos, Renato y David L. Carvajal, 2011, Ley sB 1070, documental.

Doty, Roxanne, 2007, "States of Exception on the Mexico-U. S. Border: Security, 'Decisions', and Civilian Border Patrols", en International Political Sociology, vol. 1, núm. 2, pp. 113-137.

Durand, Jorge, 2011, "Capital étnico y migración de relevo: nuevos y viejos patrones migratorios en América Latina”, en Migraciones Internacionales, vol. 6, núm. 1, México.

Edinger, Steven T., 2004, Camino de Mixtepec. Historia de un pueblo en las montañas de la Mixteca y su encuentro con la economía norteamericana, Asociación Cívica Benito Juárez, Fresno.

Esposito, Roberto, 2011, Bíos: biopolítica y filosofía, Amorrortu, Buenos Aires.

Fanon, Frantz, 2007, Los condenados de la tierra, Fondo de Cultura Económica, México.

Fisher, Lloyd Horace, 1953, The Harvest Labor Market in California, Harvard University Press, Cambridge.

Foucault, Michel, 1978, Historia de la sexualidad I. La voluntad de saber, Siglo XXI, México.

——, 2006, Seguridad, territorio, población, Fondo de Cultura Económica, Buenos Aires.

2008, La verdad y las formas jurídicas, Gedisa, Barcelona.

Glick Schiller, Nina, Linda Basch y Cristina Blanc-Szanton (eds.), 1992, Towards a Transnational Perspective in Migration: Race, Class, Ethnicity, and Nationalism Reconsidered, Johns Hopkins University Press (Annals of the New York Academy of Sciences, vol. 645), Nueva York.

Goldschmidt, Walter, 1947, As you Sow, The Free Press, Glencoe.

Gramsci, Antonio, 1999, "El problema de la dirección política en la formación y desarrollo de la nación y del Estado moderno en Italia”, en Cuadernos de la Cárcel, vol. 5 (Cuaderno núm. 19, 1934-1935), Era, México.

H. Congreso de la Unión, 2011, Diario de los Debates, 29 de junio, Segundo Receso de la Comisión Permanente, H. Congreso de la Unión, México.

Hall, Stuart, 1990, “Cultural Identity and Diaspora”, en Jonathan Rutherford, Identity: Community, Cultural, Difference, Lawrence \& Wishart, Londres.

Hollifield, James F., 2004, "The Emerging Migration State”, en International Migration Review, vol. 38, núm. 3, The Center for Migration Studies of New York, pp. 885-912.

Huízar Murillo, Javier e Isidro Cerda, 2004, "Indigenous Mexican Migrants in the 2000 U. S. Census: 'Hispanic American Indians”, en Jonathan Fox y Gaspar Rivera-Salgado (comps.), Indigenous Mexican Migrants in the United States, Center for U. S.-Mexican Studies-University of California San Diego, La Jolla.

Instituto Centroamericano de Estudios Sociales y Desarrollo (Incedes) y Sin Fronteras, 2011, "Estudio comparativo de la legislación y políticas migratorias en Centroamérica, México y República Dominicana”, Instituto Centroamericano de Estudios Sociales y Desarrollo, Sin Fronteras, México.

Instituto Nacional de Migración (INM), 2005, "Propuesta de política migratoria integral en la frontera sur de México", en línea: <http://www. politicamigratoria.gob.mx/es_mx/SEGOB/Propuesta_de_politica_migratoria_integral_en_la_frontera_sur_de_Mexico>, consultado en marzo de 2014.

Kearney, Michael, 1996, Reconceptualizing the Peasantry. Anthropology in Global Perspective, Westview Press, Boulder.

y Carole Nagengast, 1989, "Anthropological Perspectives on Transnational Communities in Rural California”, en Working Group on Farm Labor and Rural Poverty-California Institute for Rural Studies (Working Paper, núm. 3), Davis.

Lasswell, Harold D., 1941, "The Garrison State”, en The American Journal of Sociology, vol. 46, núm. 4, University of Chicago Press, pp. $455-468$. León-Portilla, Miguel, 2006, "Movimientos de pueblos", en El País, 2 de noviembre.

Link, Daniel, 2009, “Un encuentro con Giorgio Agamben”, en Antroposmoderno, en línea: <http://www.antroposmoderno.com/antro-articulo. php?id_articulo=605>, consultado en octubre de 2012.

Locas, Marie-Chantal, 2011, "An(Other) History of the U. S.-Mexico Border: Securitization, Control, Resistance", ponencia, Western Political Science Association 2011 Annual Meeting, en línea: <http://ssrn.com/abstract=1767038> 
Marx, Karl, 2001, "Manuscritos económicos y filosóficos de 1844", en línea: <http://www.marxists.org/espanol/m-e/1840s/manuscritos/index. htm>, consultado en marzo de 2014.

McWilliams, Carey, 1935, Factories in the Field. The Story of Migratory Farm Labor in California, Archor Books, San Francisco.

Méndez y Mercado, Leticia, 1985, Migración: decisión involuntaria, Instituto Nacional Indigenista, México.

Nancy, Jean-Luc, 2007, La comunidad enfrentada, La Cebra, Buenos Aires.

Organización Internacional para las Migraciones (OIM), 2010, "El 'Informe sobre las migraciones en el mundo 2010', de la olm, destaca que es preciso invertir ahora para la migración del futuro", en línea: <http://www.iom.int/cms/es/sites/iom/home/news-and-views/news-releases/news-listing/invest-now-for-tomorrows-migrati.html>, consultado en marzo de 2014.

Palerm, Juan Vicente, 1997, "The Expansion of California Agriculture and the Rise of Peasant-Workers Communities", en Susanne Jonas y Suzanne Dod Thomas, Immigration: A Civil Rights Issue for the Americas, Scholarly Resources, Wilmington.

, 1998, "Las nuevas comunidades mexicanas en los espacios rurales de Estados Unidos: a propósito de una reflexión acerca del quehacer antropológico", Center for Chicano Studies-University of California, Santa Barbara, mimeografiado.

Pallitto, Robert y Josiah Heyman, 2008, "Theorizing Cross-Border Mobility: Surveillance, Security and Identity", en Surveillance and Inequality, vol. 5, núm. 3, pp. 315-333, en línea: <http://www.surveillance-and-society.org>.

Rouse, Roger, 1989, "Mexican Migration to the United States: Family Relations in the Development of a Transnational Migrant Circuit", tesis de doctorado en antropología, Stanford University, Stanford.

Said, Edward W., Orientalismo, 2003, Debolsillo, Barcelona.

Sousa Santos, Boaventura de y Mauricio García Villegas, 2004, El caleidoscopio de las justicias en Colombia: análisis socio-jurídico, Siglo del Hombre, Universidad de los Andes, Bogotá.

Tirman, John (ed.), 2004, The Maze of Fear: Security and Migration After 9/11, New Press, Nueva York.

Wright, Emily M. y Michael L. Benson, 2010, "Immigration and Intimate Partner Violence: Exploring the Immigrant Paradox", en Social Problems, vol. 57, núm. 3, University of California Press, pp. 480-503.

Yarrington, María Antonieta, 2013, "Diálogo de sordos. La lucha de una ong por asignarle significados acorde a los derechos humanos a la legislación migratoria”, tesis de maestría en antropología social, Universidad Iberoamericana, México. 